DOI: 10.2478/romneu-2014-0012

\title{
Large cerebello-pontine epidermoid tumor in a child
}

\author{
Amit Agrawal $^{1}$, Nitish Baisakhiya ${ }^{2}$, P.T. Deshmukh ${ }^{3}$, S.R. Joharapurkar ${ }^{4}$, \\ Prasenjit Mukherjee ${ }^{5}$ \\ ${ }^{1}$ Associate Professor in Neurosurgery, Department of Surgery, Datta Meghe Institute of \\ Medical Sciences, Sawangi (Meghe), Wardha (India) \\ ${ }^{2}$ Assistant Professor in ENT, Department of ENT, Datta Meghe Institute of Medical Sciences, \\ Sawangi (Meghe), Wardha (India) \\ ${ }^{3}$ Professor in ENT, Department of ENT, Datta Meghe Institute of Medical Sciences, Sawangi \\ (Meghe), Wardha (India) \\ ${ }^{4}$ Professor and Director, DMDPGME \& R, Datta Meghe Institute of Medical Sciences, \\ Sawangi (Meghe), Wardha (India) \\ ${ }^{5}$ Registrar in Surgery, Department of Surgery, Datta Meghe Institute of Medical Sciences, \\ Sawangi (Meghe), Wardha (India)
}

\begin{abstract}
Cerebellopontine angle lesions are more commonly found in adults; however, they are uncommon in children. 13 year female child presented with progressive cerebellar signs and decreased hearing in left ear. Magnetic resonance imaging was suggestive of left cerebello-pontine angle epidermoid tumor that was treated surgically. In this rare case we discuss the imaging findings and review the relevant literature.
\end{abstract}

Key words: Cerebellopontine angle, Brain tumors, Children, Epidermoid

\section{Introduction}

Cerebellopontine angle (CPA) lesions are more commonly found in adults; however, they are uncommon in children. (1) We report a rare occurrence of epidermoid tumor in a child, discuss the imaging findings and review the relevant literature.

\section{Case report}

This 13 year female child presented with history of difficulty in walking for last one and half year, pain both lower limbs since last 1 year and swaying to either side more on left side of last 6 months duration. She also noticed decreased hearing in left ear for last three months. There was no history of focal weakness, seizures, headache, vomiting or bowel and bladder disturbances. Here general and systemic examination was unremarkable. Higher mental functions were normal. Fundus and vision was normal. Cranial examination revealed left $6^{\text {th }}, 7^{\text {th }}$ and $8^{\text {th }}$ cranial nerve paresis and bilateral bilateral $5^{\text {th }}$ nerve weakness. There were bilateral cerebellar signs more on left side. All deep 
tendons exaggerated and planters were extensor. Motor and sensory examination was normal. Blood investigations were normal and audiometry showed sensorineural deafness in left ear. Magnetic resonance imaging (MRI) of the brain showed left sided cerebello-pontine angle which was hypo-and hyperintense on $\mathrm{T} 1$ and T2 weighted images, respectively. On diffusion weighted (DW) MRI, the lesion was hyperintense, which suggested that they were a cerebello-pontine angle epidermoid tumour (figures 1 and 2).

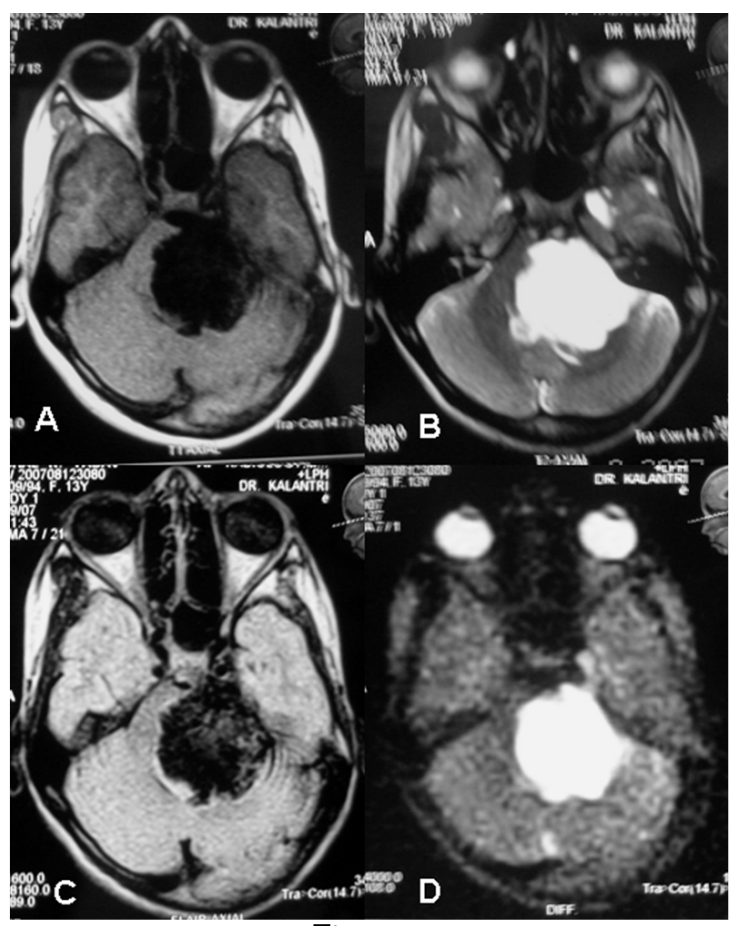

Figure 1

MRI brain, the lesion in hypointense on T1 image (A), hyperintense on T2 image (B), hypointense on FLAIR image with honeycomb appearance (C) and hyperintense on Diffusion-Weighted images (D)

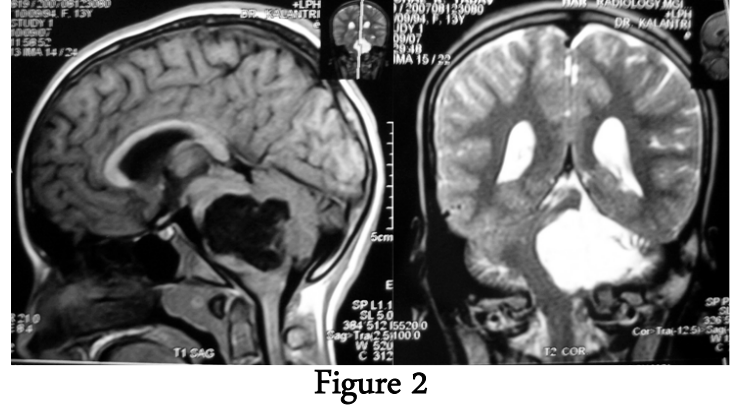

MRI T1 saggital image (left) and T2 coronal image (right)

The patient underwent a left suboccipital retrosigmoid craniotomy, which showed a classical pearly tumour encasing the branches of the basilar artery and anterior inferior cerebellar artery. A subtotal removal of the cyst contents was achieved because some of the areas of the lesion were inaccessible. Similarly, some of the capsule was excised, but capsule that was densely adherent to the brain stem was left in place. Postoperatively the patient had new left-sided seventh nerve palsy despite anatomical continuity of the nerve. She otherwise made an unremarkable recovery except minimal would leak that was managed conservatively.

\section{Discussion}

Epidermoid cyst, or pearly tumor, is congenital in origin and accounts for about $1 \%$ of intracranial tumors. (2) Though the $\mathrm{CPA}$ is the most common intracranial location for an epidermoid inclusion cyst, (3) these lesions are rare in children. $(1,4)$ An epidermoid tumor is a congenital lesion that arises from inclusion of ectodermal epithelial elements. (5) The 
natural history of epidermoid cysts is well described. They are benign tumors of embryonal origin, usually occur in isolation, and constitute $1 \%$ of all intracranial tumors. $(6,7)$ Epidermoid cysts arise from normal epithelial cells included during neural tube closure and their growth is due to accumulation of keratin and cholesterol produced by desquamation of the squamous epithelium lining the mass. These slow-growing tumors encase and surround nerves and arteries in the cisterns rather than displacing them. (5) Grossly, epidermoid tumors are typically well defined lesions with an irregular nodular outer surface and a shiny "mother of pearl" appearance. (8, 9) Epidermoid tumours have a thin capsule consisted of stratified keratinised squamous epithelium without vascularity. $(5,10)$ This thin capsule may rupture spontaneously and can cause bouts of chemical meningitis. (10) Patients with an epidermoid usually present in the 4th and 5 th decades of life. (11) The cerebellopontine angle epidermoids cause symptoms and signs of a slowly expanding mass lesion and may present with symptoms of cranial nerve, cerebellar, and brain stem compression as well as with obstructive hydrocephalus and meningeal irritation. (12, 13) Intracranial epidermoid cysts can closely mimic cerebrospinal fluid on magnetic resonance imaging and computed tomography. (14) Epidermoid cysts typically show undulating margins and model their shape to conform to the cerebropontine angle. The cyst has a tendency to insinuate itself around the nerves and blood vessels in the cerebropontine angle. (14) On CT scans, epidermoid cysts appear hypoattenuating, almost isoattenuating to CSF, and have characteristic irregular, lobulated margins. (15) On MR imaging, epidermoid tumors typically have low signal intensity on T1weighted images, high signal intensity on T2-weighted images, and no enhancement on gadolinium-enhanced images. $(5,15$, 16) On diffusion-weighted imaging epidermoid cysts have high signal intensity unlike arachnoid cysts, those have very low signal intensity. (16) Differentiation of epidermoid tumors particularly from arachnoid cysts is important for appropriate patient care because the treatment is different for each lesion. (16) The differential diagnosis of the cerebellopontine angle includes acoustic neurilemoma, meningioma, epidermoid tumor, and other rare neoplasms involving this region. (17) The treatment of choice or CP angle epidermoid is surgical resection, however complete excision of the tumor capsule is often not possible due to the high risk of damaging adherent neural or vascular structures. (12) As a consequence, there are a number of these lesions that recur, usually many years after the original surgery. (6) In our case MRI facilitated the diagnosis of CP angle epidermoid and accordingly surgical approach could be planned. Also preoperative knowledge is important to avoid chemical meningitis. (15) 
Address for correspondence:

Dr Amit Agrawal

Associate Professor (Neurosurgery)

Clinical and Administrative Head

Division of Neurosurgery

Datta Meghe Institute of Medical Sciences

Sawangi (Meghe)

Wardha-442005,

Maharashtra, India.

Phone: +91-7152-3956552

Fax: $+91-7152-2245318$

Email:dramitagrawal@gmail.com

\section{References}

1. Zuccaro G, Sosa F. Cerebellopontine angle lesions in children. Childs Nerv Syst. 2007; 23(2):177-83.

2. Hsieh CH, Huang KM, Kao MC, Peng S, Wang CC. Hemorrhage in intracranial epidermoid cyst. J Formos Med Assoc. 1996; 95(2):173-5.

3. Salazar J, Vaquero J, Saucedo G, Bravo G. Posterior fossa epidermoid cysts. Acta Neurochir (Wien). 1987; 85(1-2):34-9.

4. Resnick DK, Levy EI, Jannetta PJ. Microvascular decompression for pediatric onset trigeminal neuralgia. Neurosurgery. 1998; 43(4):804-7.

5. Gao PY, Osborn A, Smirniotopoulos J, Harris CP. Epidermoid tumor of the cerebellopontine angle. AJNR Am J Neuroradiol 1992; 13:863-872.

6. Berger MS, Wilson CB. Epidermoid cysts of the posterior fossa. J Neurosurg 1985;62:214-219

7. Yamakawa K, Shitara N, Genka S, Manaka S, Takakura K. Clinical course and surgical prognosis of 33 cases of intracranial epidermoid tumors. Neurosurgery 1989;24: 568-573

8. deSouza CE, deSouza R, da Costa S, Sperling N, Yoon TH, Abdelhamid MM, Sharma RR, Goel A. Cerebellopontine angle epidermoid cysts: a report on 30 cases. J Neurol Neurosurg Psychiatry. 1989; 52(8):98690.

9. Ochi M, Hayashi K, Hayashi T, Morikawa M, Ogino A, Hashmi R, Iwanaga M, Yasunaga A, Shibata S. Unusual CT and MR appearance of an epidermoid tumor of the cerebellopontine angle. AJNR Am J Neuroradiol. 1998; 19(6):1113-5.

10.Yilmazlar S, Kocaeli H, Cordan T. Brain stem stroke associated with epidermoid tumours: report of two cases. J. Neurol. Neurosurg. Psychiatry 2004; 75; 13401342.

11.Rubinstein U. Tumors ofthe central ncrvous system. In: Atlas of tumor pathology, fasc 6, ser 2. Washington, DC: Armed Forces Institute of Pathology, 1972; 288292.

12.Samii M, Tatagiba M, Piquer J, Carvalho GA. Surgical treatment of epidermoid cysts of the cerebellopontine angle. J Neurosurg 1996;84:14-19

13.Russel DS, Rubinstein LJ. Tumors and tumor like lesions of maldevelopmental origin. In: Russel DS, Rubinstein LJ, eds. Pathology of tumors of the nervous system, 5th ed. London: Edward Arnold, 1989:693-5.

14.Atalar MH, Sener RN, Icagasioglu D. Epidermoid cyst in a girl: Constructive interference in steady-state and diffusion-weighted imaging findings. Journal of Pediatric Neurology 2006; 4 (3):211-214.

15.Chen CY, Wong JS, Hsieh SC, Chu JS, Chan WP. Intracranial epidermoid cyst with hemorrhage: $\mathrm{MR}$ imaging findings. AJNR Am J Neuroradiol. 2006; 27(2):427-9.

16.Nguyen JB, Ahktar N, Delgado PN, Lowe LH. Magnetic resonance imaging and proton magnetic resonance spectroscopy of intracranial epidermoid tumors. Crit Rev Comput Tomogr. 2004; 45(5-6):389427.

17.Bonneville F, Sarrazin JL, Marsot-Dupuch K, Iffenecker C, Cordoliani YS, Doyon D, Bonneville JF. Unusual lesions of the cerebellopontine angle: a segmental approach. Radiographics. 2001; 21(2):419-38. 